\title{
APONTAMENTOS SOBRE O PROCESSO DE ALFABETIZAÇÃO E LETRAMENTO NA EJA: RELATOS DE ALUNOS E PROFESSORES
}

\section{APPOINTMENTS ON THE PROCESS OF LITERACY AND LETTERING IN THE EJA: STUDENT AND TEACHER STORIES}

\author{
Verônica Barbosa Andrade \\ Professora da rede pública municipal de Naviraí-MS \\ veronicawve@gmail.com
}

Vivianny Bessão de Assis

Doutora em Educação

Professora da Fundação Universidade Federal de Mato Grosso do Sul (UFMS), campus de Naviraí viviannybessao@gmail.com

\begin{abstract}
Resumo
O presente estudo teve por objetivo entender as possíveis necessidades e expectativas dos adultos no processo de alfabetização e letramento na Educação de Jovens e Adultos (EJA). O estudo baseou-se em pesquisa bibliográfica e pesquisa de campo de natureza qualitativa em duas escolas na região sul do estado de Mato Grosso do Sul (MS), por meio de entrevistas semiestruturadas e questionários entregues a duas professoras que atuam na $1^{\mathrm{a}}$ e na $2^{\mathrm{a}}$ fases do ciclo de alfabetização da EJA, bem como aos alunos acima de 35 anos que frequentavam essas duas escolas. Os resultados da pesquisa indicam que os adultos progredirem nas etapas da EJA sem o devido domínio da leitura e da escrita. Com isso, suas expectativas com a alfabetização não são atendidas.
\end{abstract}

Palavras-chave: EJA; Alfabetização e Letramento; Dificuldades de aprendizagem.

\begin{abstract}
This study aimed to understand the possible needs and expectations of adults in the process of literacy and literacy in Youth and Adult Education (EJA). The study was based on bibliographic research and qualitative field research in two schools in the southern region of the state of Mato Grosso do Sul (MS), through semi-structured interviews and questionnaires delivered to two teachers who work in the 1st and 2nd phases of the EJA literacy cycle, as well as to students over 35 who attended these two schools. The survey results indicate that adults progress in the stages of YAE without proper mastery of reading and writing. As a result, their expectations with literacy are not met.
\end{abstract}

Keywords: EJA; Literacy; Learning difficulties. 


\section{Introdução}

Esta pesquisa situa-se no âmbito da alfabetização na Educação de Jovens e Adultos (EJA), uma modalidade de ensino que se dedica a oportunizar a educação básica aos indivíduos que por diversos motivos não puderam concluir seus estudos no tempo esperado. Com isso, a EJA é a base para que consigam chegar a uma sociedade igualitária em termos de oportunidades e qualidade de vida. Atualmente, há diversas pessoas que buscam a EJA com esse intuito, pois vivem inseridas em um mundo letrado, e se faz necessário o domínio da leitura e da escrita para progredirem no mercado de trabalho. Esse fato tem sido observado como um dos principais motivos do retorno dos adultos às escolas.

Neste texto, apresentam-se os resultados de um estudo que buscou compreender os desejos e expectativas de alunos adultos envolvidos no processo de alfabetização na EJA. O interesse em desenvolver esta pesquisa teve início a partir das reuniões da linha "Leitura, Escrita e Literatura", do Grupo de Estudos e Pesquisa em Prática Educativa e Tecnologia Educacional (GEPPETE), no qual foram realizados estudos sobre temas como evasão escolar nas fases iniciais da EJA, práticas de alfabetização, dentre outros. Essas reflexões suscitaram algumas indagações, tais como: Quais aspectos interferem no sucesso ou no fracasso da alfabetização na EJA? Qual metodologia é mais indicada para essa modalidade de ensino? Para que essas perguntas pudessem ser respondidas, foi necessário um trabalho de investigação in loco com alunos e professores, etapas que serão descritas neste texto.

Para o aprofundamento do estudo sobre o tema, buscamos referências teóricas de pesquisadores que investigaram essa temática e que contribuíram para uma compreensão mais ampla sobre o desenvolvimento da EJA e de algumas leis que regulamentaram essa modalidade de ensino. Dessa forma, o presente estudo encontra-se assim organizado: inicialmente apresenta-se a fundamentação teórica para melhor entender a temática da EJA no Brasil e as práticas atuais de alfabetização; em seguida descreve-se a metodologia utilizada para realizar a investigação, com explicações sobre o tipo de pesquisa, o instrumento utilizado para a coleta de dados e os participantes da pesquisa de campo; na sequência são apresentados os resultados e discussão fundamentados em autores que investigam temáticas relacionadas à EJA e à alfabetização de adultos; por fim são apresentadas as considerações finais e referências utilizadas para a elaboração deste trabalho de pesquisa.

\section{Fundamentação teórica}

\subsection{Apontamentos sobre o desenvolvimento da EJA no Brasil}

No período Republicano a população, em sua maioria, era analfabeta e, como consequência desse fato, a Constituição da República dos Estados Unidos do Brasil, de 1891, proibiu os adultos analfabetos de exercerem o direito político de votar. Foi somente com a Constituição de 1934, no período Vargas ${ }^{1}$, que a Educação para os adultos começou a ser reconhecida, pois se estabeleceu que o ensino primário integral deveria ser gratuito e obrigatório inclusive para esses cidadãos (HADDAD; DI PIERRO, 2000).

1 O período Vargas foi o nome atribuído ao período do presidente Getúlio Dornelles Vargas, marcado pelo nacionalismo e populismo que durou 15 anos seguidos, de 1930 a 1945. 
Um período marcante para o desenvolvimento da EJA foi entre os anos de 1959 e 1964, momento histórico em que ocorreram várias campanhas de alfabetização relacionados à EJA, como o Movimento de Educação de Base (MEB)², o Centro Popular de Cultura (CPC) $)^{3}$ e também o Programa Nacional de Alfabetização (PNA)4, do Ministério da Educação e Cultura (MEC), idealizado por Paulo Freire (HADDAD; DI PIERRO, 2000).

Paulo Freire foi um importante educador brasileiro que contribuiu significativamente para a educação de jovens e adultos, criando uma nova concepção de alfabetização como prática de liberdade, com o objetivo de desenvolver nos educandos o entendimento crítico sobre a sociedade em que se vive. Paulo Freire criou uma concepção filosófica de formação do sujeito, e não um método de alfabetização em si:

[...] criou uma concepção de alfabetização, no quadro de uma também nova concepção de educação [...] uma concepção de educação como prática da liberdade, educação como conscientização [...] uma concepção de alfabetização, como meio de democratização da cultura, como oportunidade de reflexão sobre o mundo e a posição e lugar do homem. [...] (SOARES, 2011, p. 119, grifos da autora).

Em meio à ditadura civil-militar brasileira (1964-1985), a concepção de educação que Paulo Freire idealizava foi rechaçada, pois se tratava de uma educação popular, oposta à concepção de educação da ditadura. Nessa época, o ensino escolar não era democrático, havendo conflitos entre universidades e o poder vigente, o que resultou em pressões políticas. Nesse contexto, surgiu a Lei da Reforma do Ensino de Primeiro e Segundo Graus n. 5.692/71, que tratava do ensino supletivo em seu art. 24, garantindo o ensino escolar para os jovens e adultos que não tiveram oportunidades de estudar no tempo certo (MOURA, 2007).

Depois que essa lei foi criada, houve um grande aumento de cursos e exames supletivos para jovens e adultos. Esses cursos tinham como objetivos:

1. Suplência com a função compensatória, recuperar o tempo perdido por meio de cursos e exames, respeitando o critério de idade para efeito de certificação, 18 e 21 anos respectivamente para o ensino de primeiro e segundo grau;

2. Suprimento com a função de aperfeiçoamento ou atualização;

3. Aprendizagem voltada para a formação metódica do trabalho, desenvolvida pelas empresas ou instituições por estas criadas e mantidas;

4. Qualificação tendo como base obrigatória os cursos e não os exames visava a profissionalização, sem preocupar-se com a educação geral. Buscando, assim, o perfil de trabalhador, fiel ao sistema (MOURA, 2007, p. 53).

\footnotetext{
2 Movimento de Educação de Base foi criado pela Conferência Nacional dos Bispos do Brasil (CNBB), uma entidade civil de direitos privados e sem fins lucrativos. Sua missão é colaborar para o progresso humano integral e superar desigualdades sociais através de programas de educação popular libertadora ao longo da vida. Fundado em 21 de março de 1961, este órgão realiza ações diretas de educação popular em áreas populacionais do país onde há situação de pobreza. As ações de mobilização social, de alfabetização de jovens e adultos e de educação de base são de responsabilidade de equipes regionais em cada uma das unidades da federação onde atuam.

3 O Centros Populares de Cultura - foi formado em março de 1962 no Rio de Janeiro por intelectuais vinculados à União Nacional de Estudantes (UNE). Tinha como objetivo criar e divulgar uma arte popular revolucionária, a qual toda a forma de manifestação cultural deveria ser compreendida pelas grandes classes populares e não somente pelas classes dominantes. (GADOTTI, 2014).

4 Programa Nacional de Alfabetização (PNA) - foi idealizado por Paulo Freire para combater o analfabetismo, o qual prevista a necessidade da participação da classe popular nesta causa. O programa se concretizaria a partir de projetos pilotos em regiões Nordeste, Sul e Sudeste "[...] O programa previa a criação de 60.870 Círculos de Cultura, cada um com duração de três meses, em todas as unidades da Federação, para alfabetizar, em 1964, 1.834.200 analfabetos na faixa entre 15 e 45 anos. [...]" (GADOTTI, 2014, p. 205). Seria criado em 21 de janeiro de 1964, porém sua implantação não chegou a se efetivar, devido a proposta ser oposta ao ponto de vista que a ditadura tinha sobre a educação.
} 
Observa-se que nesse período a EJA reduzia-se a aprendizagens técnicas voltadas para a atuação no mercado de trabalho. O supletivo favoreceu a iniciativa privada e a prática de educação domesticadora, contra a qual se erguia Paulo Freire. Ainda na ditadura militar foi criado o Movimento Brasileiro de Alfabetização (MOBRAL), com a proposta de erradicar a alfabetização no Brasil. O MOBRAL foi criado para substituir a concepção de alfabetização de Paulo Freire, pois "A Educação Popular, estreitamente associada à Cultura Popular [...] foi perseguida e criminalizada [...]" (GADOTTI, 2014, p. 203).

No período da redemocratização brasileira (após 1985), a Constituição de 1988 foi elaborada trazendo direitos para a EJA. Com a "Nova República", o MOBRAL foi substituído pela Fundação Nacional para a Educação de Jovens e Adultos (EDUCAR), que foi implantada com o objetivo de desenvolver e aplicar programas de alfabetização para a educação básica destinados às pessoas que não tiveram a acesso à escola. Essa fundação formulou projetos que orientaram a execução dos programas, incentivando a população por meio da valorização dos professores e capacitando-os para o ensino (BRASIL, 1985).

No ano de 1996 foi criada a lei do Fundo de Manutenção e Desenvolvimento do Ensino Fundamental e de Valorização do Magistério (FUNDEF), n. 9.424/96, a qual teve por objetivo destinar fundos para o ensino fundamental, porém desamparava a EJA. O ensino médio e a educação infantil passaram a concorrer entre si pelos recursos públicos não retidos pelo FUNDEF (HADDAD; DI PIERRO, 2000).

Nesse mesmo ano foi aprovada uma nova Lei de Diretrizes e Bases da Educação Nacional (LDB), $n^{\circ}$ 9.394, que, na seção cinco, tratava especificamente da EJA e, comparando-a com a legislação anterior, a mudança está "[...] na abolição da distinção entre os subsistemas de ensino regular e supletivo, integrando organicamente a educação de jovens e adultos ao ensino básico comum" (HADDAD; DI PIERRO, 2000, p. 122).

A EJA, destinada a público-alvo de baixa renda, teve três programas de nível federal instalados nos anos de 1990, todos com o intuito de expandir a alfabetização. São eles: o Programa Alfabetização Solidária (PAS), de 1996, que teve o objetivo de reduzir os índices de analfabetismo; o Programa Nacional de Educação na Reforma Agrária (PRONERA), de 1998, cujo objetivo era a alfabetização de trabalhadores do campo, e o Plano Nacional de Formação do Trabalhador (PLANFOR), de 1996, que se destinava a uma formação de qualificação profissional que não substituía a educação básica (HADDAD; DI PIERRO, 2000).

Com o parecer de n. 11/2000 do Conselho Nacional de Educação (CNE), o Ensino Supletivo passou a ser chamado de Educação de Jovens e Adultos, denominação atual da modalidade, tornando-se parte integrada da educação básica gratuita como direito público (MOURA, 2007). No próximo tópico, abordaremos a forma como está estruturada atualmente essa modalidade de ensino e o perfil dos alunos que a frequentam.

\subsection{EJA na atualidade e o perfil dos alunos que a frequentam}

O que de fato é a EJA na atualidade? A EJA é uma modalidade de ensino que oferece a educação básica aos jovens e adultos, direito assegurado pela Constituição da República Federativa do Brasil de 1988. O art. 208 traz a obrigatoriedade do Estado em garantir a oferta de estudo na educação básica gratuita a quem não obteve a conclusão dos estudos em idade própria (BRASIL, 1988). Por meio desse ensino, "[...] os jovens e adultos foram convidados a retornar à escola a fim de preencherem a lacuna deixada pela falta de acesso, permanência e oportunidade, reparando uma injustiça social que é secular" (MOURA, 2007, p. 55). 
A atual LDB ( $n^{\circ}$. 9.394/96), em seu art. 38, especifica a idade mínima exigida para cursar a EJA sendo de 15 anos completos para o ensino fundamental e 18 anos completos para o ensino médio (BRASIL, 1996). Numa caracterização geral, da maioria do público da EJA no Brasil, esse estudante é de "[...] origem humilde, filho de pais com nível de instrução escolar incipiente ou sem nenhuma passagem pela escola [...] relacionado às responsabilidades assumidas por ele no contexto social e ao baixo nível de escolaridade que possuem [...]" (MOURA, 2007, p.57). Portanto, a EJA é composta por um público de pessoas humildes que buscam melhorar sua qualidade de vida pela conclusão dos estudos.

No art. 37 da LDB ( $n^{\circ}$. 9394/96), garante-se o ensino regular aos jovens e adultos com uma organização didática diferente da aplicada às crianças, levando em consideração suas vivências como agentes inseridos no meio social que já trazem consigo vários conhecimentos. Também garantem-se, aos alunos trabalhadores, condições para sua permanência na escola.

A educação de adultos não é uma parte complementar, extraordinária do esforço que a sociedade aplica em educação (supondo-se que o dever próprio da sociedade é educar a infância). É parte integrante desse esforço, parte essencial, que tem obrigatoriamente que ser executada paralelamente com a outra, pois do contrário esta última não terá o rendimento que dela se espera. Não é um esforço marginal, residual, de educação, mas um setor necessário do desempenho pedagógico geral, ao qual a comunidade se deve lançar (PINTO, 2010, p. 85).

De acordo com Moura (2007, p. 62), é necessário oferecer aos alunos da EJA uma educação que possibilite assumir postura ética:

[...] uma educação que prepare os jovens e adultos, não só para garantir um emprego e a empregabilidade, mas, sobretudo, que não separe escola e sociedade, conhecimento e trabalho a fim de que possam assumir posturas éticas, no desenvolvimento de responsabilidades, com compromisso crítico e reconhecimento de seus direitos e deveres.

De acordo com Freire (2009, p. 36):

[...] ensinar não pode ser um puro processo, como tanto tenho dito, de transferência de conhecimento da ensinante ao aprendiz. Transferência mecânica de que resulte a memorização maquinal que já critiquei. Ao estudo crítico corresponde um ensino igualmente crítico que demanda necessariamente uma forma crítica de compreender e de realizar a leitura da palavra e a leitura do mundo, leitura do contexto.

Na concepção idealizada por Paulo Freire, a EJA deve partir da transformação do material utilizado para a alfabetização, selecionando palavras que fazem parte do contexto vocabular dos educandos, atentando-se para as relações sequenciais dos grafemas-fonemas. Tais palavras devem ser escolhidas por conta de seus significados social, cultural e político, por meio de temas geradores, a fim de que os educandos pensem sua própria realidade (FREIRE, 2009).

Na educação formal dos adultos, deve-se ir além de simplesmente considerar os conhecimentos que eles já detêm.

O que distingue uma modalidade de educação de outra não é, portanto o conteúdo, os métodos, as técnicas de instruir (isto é o secundário, o reflexo) e sim os motivos, os interesses que a sociedade, como um todo, tem quando educa a criança ou adulto. Este é o fator primário, fundamental (PINTO, 2010, p. 74). 
Portanto, o público que frequenta a EJA é de classe popular, que volta para as salas de aulas por algum objetivo ou por necessidades que a sociedade impôs a esses indivíduos. Sendo assim, esses estudantes precisam ter respeitada a visão de mundo que trazem para o espaço escolar. A escola deve buscar, por meio da experiência trazida pelo aluno da EJA, desenvolver o letramento, pois as pessoas precisam ser capazes de ler e escrever de maneira que possam se comunicar e se expressar socialmente, ampliando sua visão de mundo. No próximo tópico são apresentadas as concepções de alfabetização e letramento na perspectiva da EJA.

\subsection{Definição de alfabetização e letramento na perspectiva da EJA}

Muito utilizadas no campo da educação, as palavras alfabetização e letramento se relacionam e se comunicam e devem andar juntas na aprendizagem de leitura e da escrita (SOARES, 2010). Muitas vezes, no entanto, são utilizadas com o mesmo significado, e algumas pessoas desconhecem a função que cada uma desempenha. Diante disso, se faz necessário definir o significado dessas duas palavras, explicitando o papel que cada um desses processos desempenha na educação.

Em síntese, o significado da palavra alfabetização é o ato de ensinar a ler e escrever. No entanto, "[a]s pessoas se alfabetizam, aprendem a ler e a escrever, mas não necessariamente incorporam a prática da leitura e da escrita [...]" (SOARES, 2010, p. 45), pois as adquirem como algo mecanizado. Desse modo, embora grande parte da população se declare alfabetizada, um novo fato foi observado: grande parte delas não conseguia utilizar os conhecimentos da alfabetização em um mundo cada vez mais letrado. Esse fenômeno foi observado e juntamente com ele surgiu a necessidade de uma nova palavra para dar nome a esse novo fato, chamado de letramento (SOARES, 2010).

Letramento é um termo traduzido do inglês literacy, cuja origem vem do latim littera. Portanto, "[...] literacyé o estado ou condição que assume aquele que aprende a ler e escrever [...]” (SOARES, 2010, p. 17). Diante dessa definição, podemos observar que é o aprendizado do letramento que oportuniza ao indivíduo a capacidade de se comunicar e socializar-se com sucesso em um contexto que exige as mais variadas práticas de leitura e a escrita de textos na sociedade.

Soares define letramento, ainda, como "[...] o resultado da ação de ensinar ou de aprender a ler e escrever: o estado ou a condição que adquire um grupo social ou um indivíduo como consequência de ter-se apropriado da escrita [...]" (2010, p. 18). Nesse sentido, estar ou ser letrado oportuniza mudanças de status social que precisam ser perceptíveis a esses sujeitos.

Ainda é preciso destacar que existe o letramento na "dimensão individual" e o letramento na "dimensão social". Do ponto de vista da dimensão individual do letramento, ler significa desde o simples ato de decodificar palavras até a habilidade de compreender textos escritos. Ler, da perspectiva da dimensão individual, compreende:

[...] a capacidade de interpretar sequências de ideias ou acontecimentos, analogias, comparações, linguagem figurada, relações complexas, anáfora; e ainda habilidades de fazer predições iniciais sobre o significado do texto, de construir o significado combinando conhecimentos prévios com as informações do texto, de controlar a compreensão e modificar as predições iniciais, quando necessário, de refletir sobre a importância do que foi lido, tirando conclusões e fazendo avaliações (SOARES, 2011, p. 31). 
Isso significa que o ato da leitura na dimensão individual leva o sujeito a compreender o que está lendo, a reconhecer os diversos tipos de textos presentes na sociedade, compreendendo a dimensão individual à qual pertence. A escrita na dimensão individual é a habilidade e os conhecimentos que um sujeito adquiriu ao se apropriar de uma vasta pluralidade de materiais escritos, pois "[...] as habilidades e conhecimentos de escrita estendem-se desde a habilidade de simplesmente transcrever sons até a capacidade de comunicar-se adequadamente com um leitor em potencial [...]" (SOARES, $2011 \mathrm{p}, 31$ ).

Já do ponto de vista da dimensão social, o letramento é uma prática social,

[...] é o que as pessoas fazem com as habilidades e conhecimentos de leitura e escrita, em determinado contexto, e é a relação estabelecida entre essas habilidades e conhecimentos e as necessidades, valores e as práticas sociais [...] um conjunto de práticas sociais associadas com a leitura e a escrita, efetivamente exercidas pelas pessoas em um contexto social específico (SOARES, 2011, p. 33, grifo da autora).

Portanto, faz-se necessário buscar uma alfabetização que caminhe junto à perspectiva do letramento, tanto individual quanto social, pois só assim teremos uma educação que contribua significativamente para o desenvolvimento integral do educando. Com base no delineamento teórico da pesquisa bibliográfica, apresentam-se a seguir os procedimentos adotados para a pesquisa de campo.

\section{Procedimentos metodológicos}

Para o desenvolvimento desta investigação, optou-se pela pesquisa de natureza qualitativa do tipo descritiva, que "[...] tem como objetivo primordial a descrição das características de determinada população ou fenômeno ou, então, o estabelecimento de relações entre variáveis" (GIL, 2008, p. 42). A pesquisa qualitativa "[...] se propõe a preencher lacunas no conhecimento, sendo poucas as que se originam no campo teórico, daí serem essas pesquisas frequentemente definidas como descritivas ou exploratórias" (ALVES-MAZZOTTI; GEWANDSZNAJDER, 2008, p. 151).

Portanto, visando compreender uma situação específica e suas variáveis, a fase inicial desta pesquisa se desdobrou da necessidade de localizar as escolas que ofertavam o ensino da EJA na cidade investigada. Consultamos a Gerência Municipal de Educação e Cultura (GEMED) para averiguar quantas escolas ofereciam o ensino da EJA. Com isso, observamos que, em uma população de 56.000 habitantes, na rede municipal de ensino havia apenas duas escolas que ofertavam essa modalidade no processo de alfabetização. Assim, realizamos a pesquisa nas duas escolas: em uma delas pesquisou-se a $1^{\text {a }}$ fase e na outra, a $2^{a}$ fase ${ }^{5}$.

Os sujeitos da pesquisa foram dezessete alunos acima de 35 anos e duas professoras que lecionavam nas respectivas fases. Realizou-se entrevista semiestruturada somente com a professora da $2^{a}$ fase da EJA, com base em um roteiro. De acordo com Ludke e André (1986), com a entrevista é possível que o entrevistador faça "[...] correções, esclarecimentos e adaptações que a tornam sobremaneira eficaz na obtenção das informações desejadas [...], a entrevista ganha vida ao se iniciar o diálogo entre o entrevistador e o entrevistado" (LUDKE; ANDRÉ, 1986, p. 34).

5 A primeira fase da EJA corresponde ao $1^{\circ} \cdot 2^{\circ}$. e $3^{\circ}$. anos do Ensino Fundamental regular, já a segunda fase corresponde ao $4^{\circ}$. e $5^{\circ}$. anos do Ensino Fundamental do ensino regular. 
Já a professora da $\mathbf{1}^{\mathbf{a}}$ fase preferiu responder às questões por meio de questionário. Neste caso, fizemos as mesmas indagações que foram feitas à professora da $\mathbf{2}^{\mathbf{a}}$ fase. Para a coleta de dados com os alunos, também optou-se pela técnica do questionário com poucas questões abertas, pois desta maneira seria possível auxiliar os alunos que tinham dificuldades na leitura e na escrita. Também utilizamos questões fechadas de múltipla escolha, porque elas apresentam possíveis respostas de forma objetiva, facilitando a análise dos dados diante de um considerável número de alunos (LAKATOS; MARCONI, 2003).

O questionário aplicado aos alunos teve um total de 13 questões, que foram respondidas em horários de aula no período noturno e visavam identificar o perfil desses alunos. Para isso, coletamos dados sobre idade, sexo, estado civil, profissão, dentre outros, dos quais trataremos brevemente em uma apresentação geral dos alunos de ambas as fases.

Também visou-se compreender as dificuldades, objetivos e expectativas com a alfabetização na EJA. Um dado a ser destacado é que, ao se realizar a coleta dos dados, os alunos de ambas as fases não conseguiram ler e responder às questões dos questionários sozinhos. Foi necessário que eles nos explicassem o que queriam escrever para que pudéssemos auxiliá-los na escrita de suas respostas.

\subsection{Caracterização dos colaboradores da pesquisa}

Conforme mencionamos, a pesquisa foi realizada em duas escolas municipais: na escola "Prof. ${ }^{a}$ Maria do Céu" ${ }^{\text {na }} \mathbf{1}^{\text {a }}$ fase da EJA, com o total de 23 alunos matriculados, e na escola "São Francisco" na $\mathbf{2}^{\text {a }}$ fase, com o total de 21 alunos. As professoras colaboradoras desta pesquisa foram denominadas Professora da $\mathbf{1}^{\mathbf{a}}$ fase e Professora da $\mathbf{2}^{\mathrm{a}}$ fase. Os alunos de ambas as fases receberam nomes fictícios: na $\mathbf{1}^{\mathrm{a}}$ fase os alunos foram chamados de Maria, Alaíde, Lurdes, Conceição, Alice, Osvaldo, Sérgio e João; na $\mathbf{2}^{\mathrm{a}}$ fase, foram chamados de Raquel, Isabel, Helena, Márcia, Cirley, Marta, Cilene, Sônia e Samuel.

Os resultados desta investigação são apresentados e discutidos a partir das seguintes categorias de análise: inicialmente apresenta-se a visão dos alunos adultos da $1^{\mathrm{a}}$ e $2^{\mathrm{a}}$ fases da EJA sobre o seu processo de alfabetização, envolvendo o autoconceito sobre suas aprendizagens e as perspectivas para o futuro. Em seguida apresentam-se as práticas pedagógicas das docentes, suas metodologias e materiais didáticos utilizados, bem como a opinião das professoras sobre as dificuldades de ensinar nessa modalidade de ensino.

\section{Resultados e discussão}

\subsection{Perfil dos alunos da EJA}

No dia em que foi realizada a pesquisa com os alunos da $\mathbf{1}^{\text {a }}$ fase da EJA, oito estavam presentes, embora houvesse 23 matriculados. Na $\mathbf{2}^{\text {a }}$ fase, nove alunos estavam presentes, em uma sala de 21 matriculados. Embora exista um maior número de alunos matriculados na EJA, poucos são frequentes, muitos faltam regularmente ou desistem na metade do ano letivo.

Com o objetivo de conhecer o púbico que frequenta a EJA, coletamos dados que tratam de identificar o perfil dos alunos pesquisados. Ao perguntarmos para os alunos de ambas as fases sobre a idade, estado civil, profissão, entre outras questões, verificamos os seguintes dados:

6 Os nomes das escolas municipais mencionadas neste texto são fictícios. 
Tabela 1: Faixa etária dos alunos da EJA

\begin{tabular}{|c|c|c|c|c|c|}
\hline \multirow{4}{*}{$1^{\mathrm{a}}$ Fase } & Idade & Núm. de alunos & \multirow{4}{*}{$2^{a}$ Fase } & Idade & Núm. de alunos \\
\hline & 35-45 anos & 3 & & 35-45 anos & 3 \\
\hline & 46-56 anos & 2 & & 46-56 anos & 5 \\
\hline & Acima de 57 anos & 3 & & Acima de 57 anos & 1 \\
\hline
\end{tabular}

Fonte: elaborado pelas autoras, 2018.

Por meio da Tabela 1, apresentada acima, foi possível identificar que os alunos das duas fases da EJA possuem uma faixa etária aproximada, porém, na $\mathbf{2}^{\mathbf{a}}$ fase, a quantidade de alunos com idade igual ou superior a 46 anos é maior.

Com a pesquisa sobre o perfil dos alunos, também identificamos a situação familiar das turmas e notamos que, na $\mathbf{1}^{\text {a }}$ fase, há um maior número de alunos com o estado civil na condição de união estável (03 alunos). Já na $\mathbf{2}^{\mathbf{a}}$ fase, há um maior número de alunos casados (04 alunos). Em relação ao número de filhos, existe pouca diferença, porém o quantitativo de filhos dos alunos da $\mathbf{2}^{\mathbf{a}}$ fase é maior que o da $1^{\text {a }}$ fase. Na primeira fase, há três alunos que têm de 1 a 3 filhos, três alunos que têm de 4 a 5 filhos e um aluno que tem mais de 06 filhos; já na segunda fase há quatro alunos que têm de 1 a 3 filhos, quatro alunos que têm de 4 a 5 filhos e um aluno que tem mais de 06 filhos.

Na Tabela 2, abaixo, apresentamos as profissões dos alunos. Com ela foi possível analisar que na $\mathbf{1}^{\text {a }}$ fase o número de alunos que têm emprego é maior que na $\mathbf{2}^{\mathbf{a}}$ fase, pois nesta existem mais alunas donas de casa. Em ambas as fases há um maior número de mulheres (05 na $1^{\mathrm{a}}$ fase e 08 na $2^{\mathrm{a}}$ fase) do que de homens (03 na $1^{\text {a }}$ fase e 01 na $2^{\mathrm{a}}$ fase).

Tabela 2: Profissões dos alunos da EJA

\begin{tabular}{|c|c|c|c|c|c|}
\hline \multirow{7}{*}{$1^{a}$ Fase } & $\begin{array}{l}\text { Profissões/ } \\
\text { Funções }\end{array}$ & Núm. de alunos & \multirow{7}{*}{$2^{a}$ Fase } & $\begin{array}{l}\text { Profissões/ } \\
\text { Funções }\end{array}$ & Núm. de alunos \\
\hline & Do lar & 2 & & Do lar & 4 \\
\hline & Doméstica & 3 & & Padeira & 1 \\
\hline & \multirow{2}{*}{$\begin{array}{l}\text { Operador de } \\
\text { Empilhadeira }\end{array}$} & \multirow{2}{*}{2} & & $\begin{array}{l}\text { Funcionário de } \\
\text { frigorífico }\end{array}$ & 1 \\
\hline & & & & Costureira & 1 \\
\hline & \multirow{2}{*}{ Motorista } & \multirow{2}{*}{1} & & Artesã & 1 \\
\hline & & & & Comerciante & 1 \\
\hline
\end{tabular}

Fonte: elaborado pelas autoras, 2018

Observa-se que as profissões dos alunos são trabalhos em que há um desgaste físico e com jornadas de trabalho muitas vezes elevadas, demonstrando assim que as dificuldades de muitos alunos da EJA são causadas em sua maioria devido ao cansaço desses alunos, pois frequentam a escola em período noturno, depois de uma longa jornada de atividades no período diurno.

No Tabela 3 identificamos que muitos dos alunos das salas pesquisadas estudaram nas décadas de 1970 e 1980, época em que desistiram porque necessitaram trabalhar para ajudar a família no sustento da casa. Como demonstra a Tabela 3, alguns alunos nem chegaram a estudar no ensino regular ou desistiram por conta de questões familiares. 
Tabela 3: Histórico escolar dos alunos da EJA

\begin{tabular}{|c|c|c|c|c|c|c|c|}
\hline & $\begin{array}{l}\text { Época que estudo } \\
\text { ensino regular do } \\
4^{\circ} \text { ano }\end{array}$ & $\begin{array}{l}\text { no } \\
{ }^{\circ} \text { ao }\end{array}$ & $\begin{array}{l}\text { Núm. de } \\
\text { alunos }\end{array}$ & & $\begin{array}{l}\text { Época que estudo } \\
\text { ensino regular do } \\
4^{\circ} \text { ano }\end{array}$ & & $\begin{array}{l}\text { Núm. de } \\
\text { alunos }\end{array}$ \\
\hline & Década de 1970 & & 5 & & Década de 1970 & & 2 \\
\hline & Década de 1980 & & 2 & & Década de 1980 & & 3 \\
\hline & Década de 1990 & & 0 & & Década de 1990 & & 0 \\
\hline & Década de 2000 & & 0 & & Década de 2000 & & 0 \\
\hline & Não frequentou & & 1 & & Não frequentou & & 4 \\
\hline & $\begin{array}{r}\text { Motivos de desis } \\
\text { da }\end{array}$ & $\begin{array}{l}\text { ncia } \\
\text { JA }\end{array}$ & os alunos & & $\begin{array}{r}\text { Motivos de desis } \\
\text { da }\end{array}$ & $\begin{array}{l}\text { ncia } \\
\text { IA }\end{array}$ & os alunos \\
\hline 1 rase & Possíveis causas & Nún & de alunos & 2"rase & Possíveis causas & Nú & de alunos \\
\hline & Trabalho & & 4 & & Trabalho & & 1 \\
\hline & Família & & 0 & & Família & & 2 \\
\hline & Falta de tempo & & 1 & & Falta de tempo & & 2 \\
\hline & $\begin{array}{l}\text { Dificuldade de } \\
\text { aprender }\end{array}$ & & 1 & & $\begin{array}{l}\text { Dificuldade de } \\
\text { aprender }\end{array}$ & & 1 \\
\hline & $\begin{array}{l}\text { Não gostou da } \\
\text { escola }\end{array}$ & & 0 & & $\begin{array}{l}\text { Não gostou da } \\
\text { escola }\end{array}$ & & 0 \\
\hline & Outros & & 2 & & Outros & & 0 \\
\hline & Não responderam & & 0 & & Não responderam & & 3 \\
\hline
\end{tabular}

Fonte: elaborado pelas autoras, 2018

Além do objetivo de traçar um perfil do aluno da EJA, ainda buscamos: conhecer necessidades dos adultos no processo de alfabetização e letramento; conhecer as práticas pedagógicas (metodologias e materiais didáticos) mais adequadas a esse perfil de aluno; compreender a percepção que os alunos têm de si mesmos em relação ao domínio da leitura e da escrita, após serem considerados alfabetizados pelo professor. Abordaremos esses aspectos nos tópicos seguintes.

\subsubsection{Dificuldades para permanecer na escola}

Por meio do questionário, os alunos da $\mathbf{1}^{\text {a }}$ fase responderam quais seriam as dificuldades enfrentadas por eles para permanecerem na escola (três alunos responderam que não tinham nenhum tipo de dificuldade). A aluna Conceição e o aluno Osvaldo apontam que suas dificuldades são o "esquecimento", indicando dificuldades de guardar na memória o aprendizado adquirido.

O restante dos alunos mencionaram três fatores, tais como: "trabalho", "dificuldade de leitura" e "cansaço". O trabalho e o cansaço mencionados nas respostas dos alunos é um dos problemas que mais ocasionam a falta e a desistência deles na EJA, mesmo para os que não trabalham, pois muitos têm diversos afazeres durante o dia.

A aluna Alice respondeu que tem dificuldade com a "leitura", mas o objetivo da $\mathbf{1}^{\text {a }}$ fase da EJA é justamente ensinar a ler e escrever. Entretanto, os alunos com idade avançada têm maiores problemas se comparados às crianças que estão em fase de desenvolvimento, portanto essa dificuldade mencionada por essa aluna é comum na alfabetização da EJA. 
Fizemos a mesma pergunta para os alunos da $\mathbf{2}^{\mathbf{a}}$ fase: quatro responderam que não tinham nenhum tipo de dificuldades para frequentar as aulas; outros quatro mencionaram o fato de conciliar o trabalho com os estudos e o cansaço físico e mental para estudar. A aluna Cirley mencionou a relação com a disciplina de matemática.

Em relação à dificuldade desses alunos para permanecerem na EJA, Da Cruz e Viana (2014, p. 23) mencionam que

[...] pode estar vinculada a diversos fatores, como, por exemplo, a incompatibilidade entre o horário das aulas com o de trabalho ou de procurar trabalho; a incompatibilidade com o horário dos afazeres domésticos; a dificuldade de acompanhar o curso; a distância entre a residência e a escola [...].

Portanto, os desafios dos alunos nessa modalidade de ensino são variados. Mesmo que o processo de aprendizagem seja um dos fatores importantes, há outras dificuldades que limitam a permanência dos alunos na EJA.

\subsubsection{Motivos que os levaram a retornar à escola}

Outro bloco de questões do questionário voltava-se aos motivos que os levaram retornar às salas de aulas. Observamos que cada aluno apontou diferentes razões para esse retorno: na $\mathbf{1}^{\mathrm{a}}$ fase. Alaíde respondeu ter sido por incentivo da família; Lurdes, por algumas experiências negativas que sofreu na sociedade; Conceição, por incentivo da família e de amigos; e cinco alunos responderam que foi por vontade pessoal. Na $\mathbf{2}^{\mathrm{a}}$ fase, as três alunas Marta, Helena e Sônia voltaram a estudar por vontade pessoal; quatro (Raquel, Márcia, Cilene e Samuel), em decorrência do incentivo da família; Cirley, por incentivo de amigos; e Isabel, devido a uma exigência do trabalho.

Esses alunos buscam na alfabetização as condições necessárias para viverem em sociedade e relatam ainda o que eles sonham em fazer após serem alfabetizados. Sobre esse aspecto, destacamos os depoimentos dos alunos da $1^{\text {a }}$ fase:

Maria: "para poder ir fazer compras";

Alaíde: "para ler e escrever";

Lurdes: "para fazer uma faculdade e ter um trabalho melhor que doméstica";

Osvaldo: "para poder tirar minha carteira $(\mathrm{CNH})$ e viajar",

Conceição: "tirar minha carteira de habilitação";

Sérgio: "para ter um trabalho melhor";

Alice: "para trabalhar em um emprego melhor";

João: "para o trabalho".

Podemos observar que as respostas dos alunos vão desde poder realizar tarefas simples do cotidiano, até cursar uma faculdade ou obter a Carteira Nacional de Habilitação $(\mathrm{CNH})$. A maioria das respostas dos alunos indica que eles buscam a alfabetização para se adequarem melhor à sociedade. Eles sentem as imposições sociais sobre a leitura e a escrita para a realização de determinadas ações básicas, como, por exemplo, dirigir ou fazer compras.

De acordo com Freire (1967), a alfabetização só terá sentido se o homem for capaz de refletir sobre si no contexto da sociedade. "Só assim nos parece válido o trabalho da alfabetização, em que a palavra seja compreendida pelo homem na sua justa significação: como uma força de transformação do mundo. Só assim a alfabetização tem sentido" (FREIRE, 1967, p. 142). A respeito do que diz Freire (1967), percebe-se que a maioria busca a alfabetização para realizar tarefas que lhes são delegadas socialmente e pela lógica do emprego, apenas. Esses alunos não compreendem o significado político e social do processo de alfabetização. 


\subsection{Autoconceito dos alunos da EJA sobre seu processo de alfabetização}

Também buscamos saber se eles perceberam mudanças em relação à leitura e à escrita desde que passaram a frequentar a escola, e todos os alunos disseram que notaram mudanças.

Na $\mathbf{1}^{\text {a }}$ fase, Maria, Conceição e João responderam: "sim, estou aprendendo";

Osvaldo: "sim, melhorei a leitura e escrita";

Lurdes: "sim, na escrita e na leitura. Já estou bem melhor";

Alaíde: "sim, já notei uma diferença";

Alice: "a leitura";

Sérgio: "leitura e escrita".

Todos demonstraram um autoconceito positivo sobre a aprendizagem da leitura e da escrita na escola, percebendo mudanças, mas é possível notar que as respostas são curtas e que demonstram muitas dificuldades em expressar-se pela escrita.

Os alunos da $\mathbf{2}^{\mathbf{a}}$ fase responderam que notaram mudanças desde que começaram a estudar. Suas respostas apontam diversas percepções, tais como:

Raquel: "sim, já melhorei”;

Isabel: "já consigo escrever o meu nome, também a ler e escrever um pouco";

Helena: "Sim, pois já sei ler e escrever muito bem";

Márcia: "percebi que hoje estou lendo melhor";

Cirley: "sim, em um mês que retornei, já sinto que estou me desenvolvendo bem";

Marta: "sim, aprendi mais";

Cirlene: "sim, melhorou no meu trabalho";

Sônia: "pouco, mas já estou escrevendo melhor";

Samuel: "sim".

As respostas dos alunos evidenciam que todos consideram que estão se desenvolvendo. No entanto, na $\mathbf{2}^{\mathbf{a}}$ fase da EJA os alunos já deveriam estar alfabetizados, e no dia em que realizamos a coleta de dados os estudantes não conseguiram ler e responder sozinhos às questões dos questionários. Para ajudá-los, foi necessário que eles nos explicassem o que queriam escrever. Para alguns, foi necessário escrevermos em uma folha, e depois eles copiaram no questionário.

No planejamento de Língua Portuguesa da EJA da $\mathbf{2}^{\mathbf{a}}$ fase, o currículo prevê os seguintes requisitos para essa aprendizagem: fazer o uso correto da ortografia; alfabeto maiúsculo e minúsculo; frases e expressões; produção e interpretação de texto de anúncios, bilhetes e cartas (Programa Curricular Municipal, 2016). Porém, os alunos pesquisados que se encontram nessa fase ainda estão longe de alcançar essa aprendizagem.

Também perguntamos se havia textos para ler na escola e se estavam sendo úteis em seu cotidiano. As alunas Raquel, Márcia e Sônia responderam "não". Já o restante dos alunos responderam que sim e deram vários exemplos, como: "já consigo ler uma placa de trânsito, nomes fáceis de loja"; "melhorou no meu trabalho"; "melhorou meu estresse"; "me interessei mais em ler", "já entendo melhor o português".

A diminuição do "estresse" mencionado na resposta de uma das alunas se relaciona ao fato de a leitura Ihe fazer bem e ajudá-la a esquecer os problemas pessoais. Na resposta de outro aluno, ele menciona que se interessou mais pela leitura, demostrando que passou a gostar de ler. De acordo com as respostas de outros dois alunos, a alfabetização tem contribuído para sua atuação na sociedade, seja no ambiente profissional ou na observação de regras de trânsito, como menciona a aluna Isabel, que notou melhoras no trabalho, e Samuel, que diz já conseguir ler placas de trânsito e alguns nomes de lojas. 
Especificamente aos alunos da $\mathbf{2}^{\mathbf{a}}$ fase, perguntamos se eles se consideravam alfabetizados. As alunas Helena, Cirley e Cilene responderam "sim". Já os outros seis alunos responderam "um pouco". Também perguntamos se eles conseguiriam produzir um pequeno texto sozinhos e três alunas responderam "sim". Helena, Isabel, Márcia e Samuel responderam "às vezes", e Sônia e Raquel responderam "não".

Ainda questionamos aos alunos se, ao lerem um texto, eles conseguiam interpretá-lo sozinhos. As alunas Cirley e Cilene responderam "sim"; quatro alunos responderam "às vezes"; Helena, "raramente"; Sônia e Raquel, "não".

Nota-se que os alunos demonstraram percepções diferentes a respeito do seu processo de alfabetização e que somente duas alunas se consideram alfabetizadas. A percepção dos alunos é que eles conseguem apenas decodificar e codificar palavras e algumas poucas frases.

Especificamente aos alunos da $1^{\text {a }}$ fase, perguntamos se achavam que algo mudaria na vida deles após concluírem a alfabetização. As respostas dos alunos foram variadas, tais como: "vou saber fazer ligações, ir ao mercado"; "muitas coisas, a gente pode ler os nomes das ruas e muito mais"; "poderei ir ao banco resolver minhas coisas"; "uma pessoa motivada"; "muita coisa. Posso fazer minha carteira de motorista que eu tanto quero"; "não vou precisar de ajudas para fazer coisas do dia a dia"; "muita coisa no trabalho".

As respostas dos alunos, em sua maioria, evidenciaram que, após serem alfabetizados, eles poderiam ter maior autonomia em afazeres comuns do dia a dia. Assim, os alunos buscam a escola como uma forma de se "adequarem" à vida em sociedade, de se sentirem de certa forma incluídos e capazes de realizar tarefas que outras pessoas conseguem fazer e eles ainda não. Desse conjunto de respostas, Alice foi a única que apresentou um aspecto emocional e de realização pessoal proporcionado pela escola, ao dizer que a alfabetização faria dela "uma pessoa motivada".

Nas respostas desses alunos, notamos que eles buscam mudar sua vida por meio da conclusão dos estudos. Também identificamos seu desejo de que a escola ofereça um nível de letramento social que permita a eles desenvolverem "[...] habilidades e conhecimentos de leitura e escrita [...]" que atendam "[...] as necessidades, os valores e as práticas sociais [...]". (SOARES, 2011, p. 33).

Na última etapa desta pesquisa buscou-se conhecer as dificuldades dos professores que ensinam na EJA. Sobre isso tratamos no tópico seguinte.

\subsection{Docentes da EJA: metodologias de trabalho e dificuldades encontradas}

Sobre suas dificuldades, a professora da $1^{\text {a }}$ fase respondeu:

Minha maior dificuldade em ministrar aula para os adultos é a dificuldade de aprendizagem que os alunos apresentam, ao mesmo tempo que querem aprender não aceitam atualizar-se às atividades diferenciadas, os alunos não são muito motivados, sempre cansados (Professora da $1^{a}$ fase, setembro de 2018).

Essa dificuldade mencionada pela professora é um dos desafios mais comuns na EJA, pois é um ensino no período noturno, e o público que frequenta as aulas vem desanimado e cansado pelo fato de serem trabalhadores e donas de casa com rotinas desgastantes.

A professora da $\mathbf{2}^{\text {a }}$ fase não apresentou nenhuma dificuldade em ministrar suas aulas na EJA; sua preocupação está em manter os alunos na sala de aula e evitar a evasão escolar. 
Olha, dificuldade, eu, como regente, como professora, eu não encontro dificuldade. A maior dificuldade que eu encontro é com o aluno; o aluno, ele vem pra EJA cansado, ele já tem uma idade avançada, já são senhores e senhoras, eu vejo que eles querem dormir dependendo da aula, se for uma aula cansativa, então eu vejo que eles ficam cansados. Então eu tenho que criar estratégias para que a aula seja uma aula atrativa, que eles não dispersam, não fique com sono, para que eles voltem e não desista, porque a maior dificuldade da EJA mesmo é a evasão e a desistência. Eles chegam até um determinado período do bimestre, eles acham que não vão acompanhar, então eles acabam desistindo, então o meu maior esforço é manter esse aluno na EJA, sempre focando em atividades dinâmicas, atividades bem atrativas para que ele permaneça (Professora da $2^{a}$ fase, setembro de 2018).

As respostas das professoras são semelhantes, pois dizem que não enfrentam dificuldades em ensinar aos alunos, mas em como lidar com o desânimo deles em relação aos estudos e com a evasão escolar. Nas respostas das professoras, percebe-se que ambas enfrentam dificuldades, apesar de não as reconhecerem, pois não sabem como manter os alunos motivados para não desistirem antes do final do ano letivo.

Com isso, perguntarmos às professoras quais as metodologias que elas utilizavam para alfabetizar esses alunos e se utilizavam algum material específico para a EJA. A professora da $\mathbf{1}^{\mathrm{a}}$ fase respondeu:

Costumo utilizar músicas, receitas, contas de água, energia, para trabalhar de acordo com a realidade dos mesmos, utilizo fatos do cotidiano para despertar a atenção para a aula, também utilizo atividades impressas para assimilação de cada um dos alunos com figuras. (Professora da $1^{\text {a }}$ fase, setembro de 2018).

A metodologia utilizada pela professora respeita a realidade e o contexto em que o aluno está inserido, como é esperado para se trabalhar com a alfabetização de adultos. Porém, no momento em que solicitamos que nos concedesse uma entrevista sobre sua prática de ensino a respeito da EJA, ela apresentou certo receio e pediu para ficar com uma cópia das questões que seriam feitas a ela e, no dia de realizarmos a entrevista, nos entregou as questões respondidas. Por essa razão, entendemos que essa professora se preparou para responder às questões, deixando dúvidas sobre a sua prática de ensino, pois, no dia de aplicar o questionário em sua turma, não percebemos essa prática que ela diz ter.

A resposta da professora da $2^{a}$ fase foi a seguinte:

Bom, a metodologia que eu uso. Eu gosto muito de usar com o adulto, eu uso o fono [método fonético], que eu gosto de ensinar o som da letra, e eu também uso o silábico, eu não deixo de mão o silábico. Dependendo da minha sala que, é da segunda fase, às vezes eu tenho que fazer ela se tornar multisseriada, eu divido ela em dois grupos, porque como eles vêm pra segunda fase, eles vêm com muita defasagem ainda, alguns ainda não sabem ler, não sabem escrever, então eu tenho que estar dividindo a sala, esse ano mesmo eu tenho a sala dividida. Já o material, tem ano que vem livro didático pra eles, esse ano ainda nós não fomos ofertados com esse livro didático, então o material que eu uso é o material da escola mesmo, que são os que nós temos na escola, que são o material dourado, temos livros didáticos, mas não específico para o adulto, nós utilizamos os livros das crianças mesmo (Professora da $2^{\mathrm{a}}$ fase, setembro de 2018).

Percebemos na fala da professora da $\mathbf{2}^{\mathbf{a}}$ fase que ela não usa o cotidiano do aluno como tema para o processo de ensino-aprendizagem, pois recorre aos livros do ensino regular destinados às crianças. Ao utilizar materiais destinados a outra faixa etária, o professor acaba por dificultar a aprendizagem 
de seus alunos, pois são indivíduos que já trazem consigo uma visão de mundo que não está sendo considerada. Em relação a esse aspecto, "[...] a diferença de procedimento pedagógico se origina da diferença no acervo cultural que possuem [...] no momento em que começam a ser instruídos pela escola [...]" (PINTO, 2010, p. 75). Portanto, o professor precisa respeitar as vivências de mundo e o conhecimento dos alunos sem qualquer tipo de infantilização, a fim de que eles tenham suas possibilidades de mobilidade social e política ampliadas.

A professora da $\mathbf{2}^{\mathbf{a}}$ fase respondeu ainda que sua sala é "dividida" em dois grupos. Ela faz isso com o objetivo de melhor atender os alunos, porque "eles vêm pra segunda fase com muita defasagem ainda, alguns ainda não sabem ler, não sabem escrever". Portanto, a professora relata uma grande dificuldade que enfrenta ao receber alunos sem os pré-requisitos necessários para avançarem na aprendizagem. Observamos com isso a atenção e preocupação da professora em ajudá-los. No entanto, quando ela diz que gosta do método fonético e "não abre mão do silábico", compreendemos o fato de os alunos terem respondido anteriormente que não se sentem capazes de interpretar ou escrever textos sozinhos, pois esses métodos priorizam a aprendizagem de palavras e frases e não de textos completos.

Outro aspecto notado nesta pesquisa é que os alunos chegam na $\mathbf{2}^{\mathrm{a}}$ fase sem os pré-requisitos exigidos para aquela etapa escolar. Segundo a professora da $1^{a}$ fase, isso ocorre porque: "[...] a idade de alguns atrapalha. Já que a sua grande maioria possui uma rotina difícil tanto pessoal como profissional que atrapalha sua aprendizagem". A professora da $\mathbf{2}^{\mathrm{a}}$ fase diz que

[...] o aprender a ler e escrever na fase adulta que eles se encontram já é bem mais complicado; a criança, ela está fluindo, ela tem a mente toda tranquila, e o adulto, não, ele já vem para escola preocupado, cansado. Então ele quer da escola, além de aprender a escrever, ele quer também ter um lazer, criar amizades, criar vínculos (Professora da $2^{\mathrm{a}}$ fase, setembro de 2018).

Por meio das respostas das professoras, tivemos a impressão de que os alunos que frequentam a EJA não são reprovados - o que acontece é que eles acabam desistindo no meio do ano, porém, quem é frequente até o final do ano letivo é aprovado, mesmo que não tenha o conhecimento mínimo necessário para avançar de fase, já que a maior preocupação é em relação à evasão dos alunos da EJA. Essa é uma das causas mais preocupantes que notamos com a pesquisa, pois como podemos formar alunos cada vez mais críticos e reflexivos, como Paulo Freire (1967) idealizava para essa modalidade de ensino, se na atualidade nos deparamos com a certificação de alunos que não conseguem ler e escrever?

Percebemos que as professoras das duas fases trabalham com uma alfabetização vinculada ao ato de decodificar e codificar as letras, formandos palavras. Não se trabalha uma alfabetização reflexiva. Além disso, elas apontam dificuldades para lidar com o cansaço e a desmotivação dos alunos, bem como a evasão na EJA, e, diante desses relatos, notamos que os alunos da $\mathbf{1}^{\text {a }}$ fase são aprovados sem serem alfabetizados, e que as metodologias que a professora da $\mathbf{2}^{\mathbf{a}}$ fase utiliza são inadequadas a essa modalidade de ensino, pois são utilizados livros didáticos destinados às crianças do ensino regular.

O desânimo, as dificuldades dos alunos e a evasão escolar da EJA podem estar relacionados a esse contexto, que é multifacetado, já que, se o ensino destinado aos alunos não consegue alcançar suas expectativas e necessidades, eles não se sentirão motivados a permanecerem na escola. 


\section{Considerações finais}

Com esta pesquisa identificamos que os alunos da EJA são em sua maioria pessoas oriundas da classe popular e que, por meio dos estudos, buscam melhorias para sua vida profissional e pessoal. $A 1^{a}$ e a $2^{a}$ fases da EJA destinam-se ao processo de alfabetização desses alunos, mas com o estudo observamos que eles se encontram com diversas dificuldades, e o professor, muitas vezes, não sabe lidar com tal situação.

As especificidades e características desse público da EJA não estão sendo levadas em consideração pela escola, pois não há materiais específicos para eles e, muitas vezes, sua experiência e visão de mundo não são incluídas em seu aprendizado. É preciso que os educadores entendam qual o objetivo real da EJA para a formação dos educandos, que é a de torná-los sujeitos dotados de capacidades e perspectivas, isso em uma vertente crítica da alfabetização.

Notamos que a alfabetização na EJA se realiza por meio de uma prática de ensino mecânica, em que o aluno vai para a escola e recebe informações que the são passadas e as absorve, ou nem chega a conseguir absorver tal ensino, pois suas dificuldades de aprendizagem vão sendo adiadas, deixadas de lado enquanto consegue dar andamento à rotina. Isso não é de fato um ensino que seja adequado ao público adulto, já que a alfabetização dos educandos deve ser conduzida para ampliar sua visão de mundo, trabalhando o letramento social, "[...] referindo-se a um conjunto de atividades sociais, que envolvem a língua escrita, e a um conjunto de demandas sociais de uso dessa língua." (SOARES, 2011, p. 30).

Essa modalidade de ensino ainda é muito carente em relação à atenção com os problemas apresentados pelos alunos, principalmente nas primeiras fases, que se dedicam à alfabetização, pois cada vez estão acelerando mais os estudos na EJA sem se preocuparem com a qualidade do ensino e com os objetivos, expectativas que as pessoas têm ao iniciar ou retomar seus estudos.

Com o estudo realizado, podemos dizer que a evasão na EJA ocorre por vários fatores, como a dificuldade de conciliação do trabalho com o estudo, entre outras, mas o principal motivo da evasão está relacionado às dificuldades apresentadas pelos alunos. Como vimos na resposta de uma das professoras, "[...] o aprender a ler e escrever na fase adulta que eles se encontram já é bem mais complicado; a criança, ela está fluindo, ela tem a mente toda tranquila, e o adulto, não [...]". Se o aluno adulto já tem dificuldades por causa da idade, e se os professores não sabem como lidar com tais dificuldades, esses estudantes não conseguem se desenvolver ou aprender, o que faz com que se sintam desanimados, desmotivados para sair de suas casas para frequentar um ensino noturno, sem terem o retorno que desejam.

Como a professora mencionou, "[...] eles chegam até um determinado período do bimestre, eles acham que não vão acompanhar, então eles acabam desistindo [...]”. Eles desistem achando que o problema de não conseguir aprender é somente deles, pois não têm conhecimento da situação em que se encontra o ensino na EJA, de modo que acabam se sentindo os culpados pelo próprio fracasso escolar. Essa percepção foi notada também nas falas das professoras, pois todas as dificuldades giram em torno dos alunos.

A alfabetização desses adultos, pelo menos no contexto desta investigação, não tem sido pensada de forma a ampliar a visão que eles têm sobre a sociedade em que vivem, e tem contribuído pouco para a emancipação de que os alunos necessitam nessa modalidade de ensino que é tão importante, mas, ao mesmo tempo, tão desamparada pelo sistema educacional brasileiro. 


\section{Referências}

ALVES-MAZZOTTI, Alda Judith; GEWANDSZNAJDER, Fernando. O método nas ciências naturais e sociais: pesquisa quantitativa e qualitativa. In: O método nas ciências naturais e sociais: pesquisa quantitativa e qualitativa. São Paulo: Pioneira, 2008. p. 148-178.

BRASIL. Câmara dos Deputados. Decreto $n^{\circ}$ 91.980, de 25 de novembro de 1985. Redefine os objetivos do Movimento Brasileiro de Alfabetização - MOBRAL, altera sua denominação e dá outras providências. Brasília: 1985. Disponível em: https://www2.camara.leg.br/legin/fed/decret/1980-1987/decreto-91980-25-novembro1985-442685-publicacaooriginal-1-pe.html. Acesso em: 22 ago. 2018.

BRASIL. Constituição da República Federativa do Brasil. Brasília: 1988. Disponível em: http://www.planalto.gov. br/ccivil_03/constituicao/constituicaocompilado.htm Acesso em: 22 maio 2020.

BRASIL. Lei de Diretrizes e Bases da Educação Nacional. Lei número 9.394, 20 de dezembro de 1996. Brasília: 1996. Disponível em: http://portal.mec.gov.br/seesp/arquivos/pdf/lei9394_ldbn1.pdf. Acesso em: 22 maio 2020.

COSSON, Rildo. Letramento político: trilhas abertas em um campo minado. E-Legis - Revista Eletrônica do Programa de Pós-Graduação da Câmara dos Deputados. Brasília: v. 7, n. 7, p. 49-58, 2011.

DA CRUZ, Neilton Castro; VIANA, Maria José Braga. Apropriação de estratégias como forma de superar obstáculos: trajetórias ininterruptas de estudantes da EJA no ensino fundamental. Revista Nupex em Educação. Teixeira de Freitas-BA: Universidade do Estado da Bahia, v. 1, n. 1, 2016. Disponível em: http://revistas.uneb.br/ index.php/nupex/article/view/2259/1574. Acesso em 23 nov. 2018.

FREIRE, Paulo; MACEDO, Donaldo. Alfabetização: leitura da palavra leitura do mundo. Rio de Janeiro: Paz e Terra, 1990.

FREIRE, Paulo. Professora, sim; tia, não: cartas a quem ousa ensinar. São Paulo: Olho d'Água, 2009.

FREIRE, Paulo. Educação como prática da liberdade. 5 ed. Rio de Janeiro: Paz e Terra, 1967.

GADOTTI, Moacir. 50 anos depois: como reverter o golpe na educação popular. Revista UniFreire. ano 2. 2 ed. p. 198-213, 2014. Disponível em: https://www.paulofreire.org/images/pdfs/revista_unifreire_2.pdf\#page=198. Acesso em: 21 mai. 2020.

GIL, Antonio Carlos. Métodos e técnicas de pesquisa social. 6. ed. São Paulo: Atlas, 2008.z

HADDAD, Sérgio; DI PIERRO, Maria Clara. Escolarização de jovens e adultos. Revista Brasileira de Educação, n. 14, p. 108-194, 2000. Disponível em: http://www.scielo.br/pdf/rbedu/n14/n14a07. Acesso em: 09 set. 2017.

KORNIS. Mônica Almeida. Centro Popular de Cultura. São Paulo: Fundação Getúlio Vargas FGV-CPDOC, 2018. Disponível em: https://cpdoc.fgv.br/producao/dossies/Jango/artigos/NaPresidenciaRepublica/Centro_Popular_ de_Cultura. Acesso em: 23 nov. 2018.

MARCONI, Marina de Andrade; LAKATOS, Eva Maria. Fundamentos de metodologia científica. 5. ed. São Paulo: Atlas, 2003. Disponível em: https://docente.ifrn.edu.br/olivianeta/disciplinas/copy_of_historia-i/historia-ii/china-eindia. Acesso em: 28 ago. 2018.

MENGA, Lüdke; ANDRÉ, M. E. D. A. Pesquisa em educação: abordagens qualitativas. São Paulo: EPU, v. 986, p. 99, 1986. Disponível em: https://edisciplinas.usp.br/pluginfile.php/4091392/mod_resource/content/1/Lud_And_ cap3.pdf. Acesso em: 28 ago. 2018.

MOURA, Maria da Glória Carvalho. Educação de Jovens e Adultos: que Educação é essa. Revista Linguagens, Educação e Sociedade, Teresina, ano 12, n. 16, p. 51-64, jan./jun. 2007. Disponível em: http://leg.ufpi.br/ subsiteFiles/ppged/arquivos/files/Revista/N\%2016/art_4.pdf. Acesso em: 15 ago. 2017.

NAVIRAÍ. Gerência Municipal de Educação Cultura e Esportes (GEMED). Planejamento de Língua Portuguesa. Listagem de conteúdos. Escola Marechal Rondon. $2^{a}$ fase da EJA. Naviraí: GEMED, 2016. 5 p. 
PINTO, Álvaro Vieira. Sete lições sobre educação de adultos. 16. ed. São Paulo: Cortez, 2010.

MEB - Movimento de Educação de Base: Saber, viver e lutar. Quem Somos. Disponível em: http://www.meb.org. br/quem-somos/. Acesso em: 23 nov. 2018.

SOARES, Magda. As muitas facetas da alfabetização. In: SOARES, Magda. Alfabetização e letramento. 6. ed. São Paulo: Contexto, 2011.

SOARES, Magda. Letramento: um tema em três gêneros. 4. ed. Belo Horizonte: Autêntica Editora, 2010.

Recebido em: 25/05/2019

Aceito em: 08/12/2020 